\title{
Temporal Changes in Clinical Practice with COVID-19 Hospitalized Patients: Potential Explanations for Better In-Hospital Outcomes
}

Kevin E. Kip, Ph.D., ${ }^{1}$ Graham Snyder, MD, SM, ${ }^{2}$ Donald M. Yealy, MD, ${ }^{3}$ John W. Mellors, MD, ${ }^{4}$ Tami Minnier, MSN, RN, ${ }^{5}$ Michael P. Donahoe, MD, ${ }^{6}$ Jeffrey McKibben, MS, ${ }^{1}$ Kevin Collins, BSBA, ${ }^{1}$ Oscar C. Marroquin, $\mathrm{MD}^{1}$

${ }^{1}$ Clinical Analytics, University of Pittsburgh Medical Center, Pittsburgh, PA

K.E.K. (kipke2@upmc.edu); J.M. (mckijc@upmc.edu); K.C. (collinskj@upmc.edu);

O.C.M (marroquinoc@upmc.edu);

${ }^{2}$ Division of Infectious Diseases, Department of Infection Prevention and Control, University of Pittsburgh School of Medicine, Pittsburgh, PA

G.S. (snydergm3@upmc.edu)

${ }^{3}$ Department of Emergency Medicine, University of Pittsburgh School of Medicine and

University of Pittsburgh Medical Center, Pittsburgh, PA

D.M.Y. (yealydm@upmc.edu)

${ }^{4}$ Division of Infectious Diseases, University of Pittsburgh School of Medicine, Pittsburgh, PA J.W.M. (jwm1@pitt.edu)

${ }^{5}$ Wolff Center, University of Pittsburgh Medical Center, Pittsburgh, PA

T.M. (minnierte@upmc.edu)

${ }^{6}$ Division of Pulmonary Medicine, Department of Medicine, University of Pittsburgh School of Medicine, Pittsburgh, PA

M.P.D. donahoem@upmc.edu

Keywords: COVID-19, clinical practice, dexamethasone, steroids, anticoagulants, mechanical ventilation, mortality, length of stay, temporal trends

Conflict of Interest Disclosure: None of the authors received any payments or influence from a third-party source for the work presented, and none report any potential conflicts of interest.

\section{Corresponding Author:}

Kevin E. Kip, Ph.D., FAAAS, FAHA

Vice President of Clinical Analytics | UPMC Health Services Division

3600 Forbes \& Meyran $\mid$ Forbes Tower, $9^{\text {th }}$ Floor, Suite 10070

Pittsburgh, PA 15213

412-864-2103

kipke2@upmc.edu 
medRxiv preprint doi: https://doi.org/10.1101/2020.09.29.20203802; this version posted September 29, 2020. The copyright holder for this

It is made available under a CC-BY-NC-ND 4.0 International license .

\begin{abstract}
Background/Aims: We reviewed demographic and clinical profiles, along with measures of hospital-based clinical practice to identify temporal changes in clinical practice that may have affected in-hospital outcomes of patients with COVID-19.

Methods: Data consisted of sociodemographic and clinical data captured in University of Pittsburgh Medical Center (UPMC) electronic medical record (EMR) systems, linked by common variables (deidentified). The analysis population included hospitalized patients (across 21 hospitals) with a primary diagnosis of COVID-19 infection during the period March 14August 31, 2020. The primary outcome was a composite of in-hospital mechanical ventilation/mortality. We compared temporal trends in patient characteristics, clinical practice, and hospital outcomes using 4 time-defined epochs for calendar year 2020: March 14-March 31 (epoch 1); April 1-May 15, (epoch 2), May 16-June 28 (epoch 3); and June 29-August 31 (epoch 4). We report unadjusted survival estimates, followed by propensity score analyses to adjust for differences in patient characteristics, to compare in-hospital outcomes of epoch 4 patients (recently treated) to epoch 1-3 patients (earlier treated).
\end{abstract}

Results: Mean number of hospital admissions was 9.9 per day during epoch 4, which was 2- to 3-fold higher than the earlier epochs. Presenting characteristics of the 1,076 COVID-19 hospitalized patients were similar across the 4 epochs, including mean age. The crude rate of mechanical ventilation/mortality was lower in epoch 4 patients (17\%) than in epoch 1-3 patients ( $23 \%$ to $35 \%$ ). When censoring for incomplete patient follow-up, the rate of mechanical ventilation/mortality was lower in epoch 4 patients $(p<0.0001)$, as was the individual component of mechanical ventilation $(p=0.0002)$ and mortality $(p=0.02)$. In propensity score adjusted analyses, the in-hospital relative risk (RR) of mechanical ventilation/mortality was lower in 
epoch 4 patients $(\mathrm{RR}=0.67,95 \% \mathrm{CI}: 0.48,0.93)$. For the outcome being discharged alive within 3,5 , or 7 days of admission, adjusted odds ranged from 1.6- to 1.7-fold higher among epoch 4 patients compared to earlier treated patients. The better outcomes in epoch 4 patients were principally observed in patients under the age of 75 years. Patient level dexamethasone use was $55.6 \%$ in epoch 4 compared to $15 \%$ or less of patients in the earlier epochs. Most patients across epochs received anticoagulation drugs (principally heparin). Overall steroid (81.7\% vs. 54.3\%, $p<0.0001)$ and anticoagulation use $(90.4 \%$ vs. $80.7 \%, p=0.0001)$ was more frequent on the day or day after hospitalization in epoch 4 patients compared to earlier treated patients.

Conclusions: In our large system, recently treated hospitalized COVID-19 patients had lower rates of in-hospital mechanical ventilation/mortality and shorter length of hospital stay. Alongside of this was a change to early initiation of glucocorticoid therapy and anticoagulation. The extent to which the improvement in patient outcomes was related to changes in clinical practice remains to be established. 
medRxiv preprint doi: https://doi.org/10.1101/2020.09.29.20203802; this version posted September 29, 2020. The copyright holder for this

It is made available under a CC-BY-NC-ND 4.0 International license.

\section{INTRODUCTION}

Since the onset of the COVID-19 pandemic, the US and countries worldwide have seen variation in reported incidence, testing patterns, case fatality rates, investigations of novel treatments, and clinical practice approaches. A few ${ }^{1-3}$ but not all ${ }^{4}$ recent non-peer reviewed reports suggested that the case fatality rate of COVID-19 infection is decreasing, and care is changing. However, there is an absence of published reports on large series of hospitalized COVID-19 patients, particularly with respect to temporal changes in clinical outcomes within the same data system.

One key intervention is mechanical ventilation, initially thought to be best started early with more severe COVID-19 respiratory finding, notably hypoxemia. Over time, informal reports note less mechanical ventilation use; potential explanations for lower rates of COVID-19 mechanical ventilation and less mortality include: (i) changing demographics of patients; ${ }^{5}$ (ii) more judicious use of starting and using mechanical ventilation; ${ }^{6}$ (iii) more frequent use of anticoagulants; $;{ }^{7,8}$ and steroids; $;{ }^{9-12}$ (iv) changing prominent disease manifestations of patients; ${ }^{13}$ (v) seasonal effects of temperature and humidity variation; ${ }^{14}$ and (vi) potential changes in viral infectivity or pathogenicity. ${ }^{15,16}$

There have been temporal changes in COVID-19 testing in addition to no national testing strategy. Early in the pandemic, only those with symptoms and a higher pretest probability of COVID-19 exposure or disease were the focus of testing. Soon thereafter, COVID-19 testing increased in many, notably populations with higher frequency of potential infection (e.g., nursing home patients as well as health care professionals), and more recently increased screening of asymptomatic patients such as those with return to college campus activities, along with more 
intensive contacting tracing (and testing) of individuals likely to have been exposed to those carrying SARS CoV2 virus. ${ }^{17-20}$

We sought to examine clinical outcomes of hospitalized COVID-19 patients in a large health care system accompanied by an assessment of demographic and clinical profiles, along with changes in hospital-based clinical practice, that have occurred since the onset of the COVID-19 pandemic in the US.

\section{METHODS}

Sources of Data. We used data routinely captured in the University of Pittsburgh Medical Center (UPMC) electronic medical record (EMR) systems. In brief, UPMC is a large academic medical center and insurer, housed principally in Pennsylvania. ${ }^{21}$ The UPMC data system has detailed sociodemographic and medical history data, diagnostic and clinical tests

conducted, surgical and other treatment procedures performed, prescriptions ordered, and billing charges on all outpatient and in-hospital encounters, with diagnoses and procedures coded based on the International Classification of Diseases, Ninth and Tenth revisions (ICD-9 and ICD-10, respectively).

We linked the primary data sources using common variables (deidentified) within the UPMC data ecosystem aggregated in its Clinical Data Warehouse (CDW) that include: (i) Medipac, the admit, discharge and transfer registration and hospital-based billing system; (ii) Cerner, the inpatient electronic medical record (EMR) for relevant clinical information for bedded patients at a UPMC inpatient hospital; (iii) Epic, the UPMC EMR for ambulatory office visits owned by UPMC (Community Medicine Inc. and (University of Pittsburgh Physicians); and (iv) Aria, the EMR utilized in most ambulatory Cancer Centers at UPMC for both radiation 
oncology and medical oncology. In calendar year 2019 among discharged UPMC hospital patients, there were 306,456 visits among 201,829 unique patients, with mean (median) age of 54 (60) years, $54 \%$ female, and median length of stay of 2.6 days.

Patient Population. We studied 139,465 patients with nucleic acid amplification tests for SARS-CoV-2 (the cause of COVID-19) during the period March 14, 2020 to August 31, 2020. Of these, the study population consisted of 1,076 patients who tested positive for COVID-19 and were hospitalized at one of 21 UPMC hospitals (see Supplemental Table S1 for listing of hospitals). Our study received formal ethics approval by the UPMC Ethics and Quality Improvement Review Committee (Project ID 2882), the ethics/oversight body for ensuring patient confidentiality and consent (including waiver of consent) for analysis and dissemination of deidentified data within the UPMC system.

Primary and Secondary Outcomes. The primary outcome for this analysis was a composite of in-hospital mechanical ventilation or mortality. We assessed in-hospital mechanical by the presence of a charge of mechanical ventilation within the Medipac billing software, specifically codes 94002 (first day of mechanical ventilation) and 94003 (each subsequent day of mechanical ventilation). Because some facilities used intensive care units for the care of COVID19 patients regardless of illness acuity, we did not use intensive care unit admission as an outcome. We assessed in-hospital mortality by the discharge disposition of "Ceased to Breathe" sourced from the inpatient Medical Record System.

Secondary outcomes included in-hospital mechanical ventilation or mortality individually and length of hospital stay (calculated by taking the difference between a discharge date time and the admission date time) available through billing within the Medipac system. Study 
investigators remained unaware of ascertainment of mechanical ventilation and mortality within the UPMC system during data collection and analysis.

Explanatory Variables. For assessment of temporal changes and prior to analyses, we categorized the study analysis period into discrete epochs based on observed empirical changes in testing patterns in the UPMC system. We chose a 4-time period classification scheme (see Figure 1), (Epoch 1: March 14-March 31, 2020; Epoch 2: April 1-May 15, 2020; Epoch 3: May 16-June 28, 2020; Epoch 4: June 29-August 31, 2020), and then collapsed the 4 epochs into 2 epochs to depict earlier (Epochs 1,2,3) versus recently admitted hospital patients (Epoch 4). For assessment of variation between epochs, we considered demographic variables, clinical history and medical comorbidities, laboratory values, vital signs, and medication use, with a focus on indicators of changing clinical practice such as use and timing of specific medications. As above, investigators were unaware of initial documentation of the explanatory variables in the EMRs.

Statistical Methods. We compared characteristics of patients across the 4 epochs using analysis of variance (ANOVA) for continuous variables and chi-square tests for categorical variables. We used the same methods to compare patterns of use of drugs and unadjusted inhospital outcomes by epoch group, while using non-parametric Wilcoxon tests used for variables with skewed distributions, in particular, days from hospital admission to initiation of specific drugs or oxygen therapies. We defined 3 binary "shorter" hospital length of stay variables for patients discharged alive as $\leq 3, \leq 5$, and $\leq 7$ days, and included only patients admitted with adequate time to meet these definitions. We used chi-square tests to compare proportions by epochs. Then, we used Kaplan-Meier survival curves to present the outcomes in-hospital mechanical ventilation/mortality and each individual component, comparing epoch 4 (recent) versus epoch 1-3 (earlier) patients by use of the log-rank test. 
We used propensity score methodology to compare in-hospital outcomes between epoch

4 versus epoch 1-3, adjusting for differences in presenting characteristics, ${ }^{22,23}$ Logistic regression models were fit using hospital admission during epoch 4 as the dependent variable with stepwise selection (at $p<0.2$ ) of measured pre-treatment explanatory variables. Resulting propensity scores (i.e. predicted probability of being in epoch 4 versus epochs 1-3) were the output and used as a continuous variable to control for confounding in Cox proportional hazards regression and logistic regression models of in-hospital outcomes. In sensitivity analyses, models were replicated with the use of inverse probability weighting (IPW), as well as 1:1 propensity score matching (PSM) with a maximum propensity score probability difference of 0.01 . We set the comparison alpha error at 0.05 without correction for multiple comparisons.

In stratified analyses, we examined potential effect modification by patient age using 3 groups defined as: (i) less than 60 years of age; (ii) 60 to less than 75 years of age; and (iii) 75 years of age and older. We did not impute missing values in any of the analyses. Methods and results are reported in accordance with The REporting of studies Conducted using Observational Routinely-collected health Data (RECORD) statement ${ }^{24}$ (see Supplemental Table 2).

\section{RESULTS}

The mean number of hospital admissions was 9.9 per day during epoch 4, which was 2to 3-fold higher than average daily admission during the earlier epochs (see Supplementary

Figure S1). The overall rate of COVID-19 testing performed in epoch 4 also was higher (Figure 1).

Presenting characteristics of patients hospitalized with COVID-19 are listed in Table 1. The mean patient age was similar across the 4 epochs (ranging from 63.0 to 65.2 years), as was 
representation by sex and race. In the earliest epoch (1) and most current epoch (4), the proportion of patients covered by UPMC health insurance was higher. Otherwise, the majority of patient characteristics were similar across the four epochs. Exceptions included a higher prevalence of COPD in epoch 2 and 4 patients, and nominally different mean hemoglobin laboratory values. Recent outpatient medication use at the time of hospital admission was similar across the 4 epochs.

Prescribing Patterns for Inpatients. Reported timing and use of medications showed changing patterns across the 4 epochs (Table 2). Specifically, the use of remdesivir peaked in epoch 3 at $31.3 \%$ and then declined to $17.8 \%$ in epoch 4 . There was an increase in the use of dexamethasone to $55.6 \%$ of patients in epoch 4 compared to $15 \%$ or less of patients in the earlier epochs. The majority of patients received anticoagulation drugs, principally heparin, and use was highest in epoch 2 and 4 patients. There was a striking difference in the timing of drug initiation, with much earlier use of dexamethasone, glucocorticoids as a class, and anticoagulation in epoch 4 patients. As depicted in Figure 2, a higher percentage of patients in epoch 4 had initiation of steroids $(p<0.0001)$ or anticoagulation $(p=0.0001)$ on the same day (Day 0$)$ or following day (Day 1) after hospital admission compared to patients admitted in epochs 1-3.

Use of Oxygen Support and In-Hospital Outcomes. More than half of all patients received oxygen therapy during their hospital stay, with the highest percentage $(73 \%)$ observed in epoch 2 patients (Table 3). Oxygen therapy started sooner in epoch 4 patients (mean of 1.9 days), and initiation of drug aerosol therapy was also sooner in epoch 4 patients (mean of 4.0 days) compared to epoch 1-3 patients (mean of 5.6 to 9.2 days). By contrast, the timing of the start of mechanical ventilation after hospital admission was longest in epoch 4 patients (mean of 3.6 days) compared to epoch 1-3 patients (mean of 1.9 to 2.3 days). Individually, the crude rate 
of use of mechanical ventilation was lower in epoch 4 patients $(11.7 \%)$ than in epoch $1-3$ patients (17\% to $22 \%$ ) as was in-hospital mortality (10.2\% vs. $14.5 \%$ to $23.6 \%$ ), recognizing that not all epoch 4 patients had been discharged. For the primary outcome, the crude rate of mechanical ventilation/mortality was lower in epoch 4 patients (17\%) than in epoch 1-3 patients (23\% to $35 \%$ ). When censoring for incomplete patient follow-up (i.e. patients admitted yet not yet discharged), rates of mechanical ventilation $(p=0.0002)$, mortality $(p=0.02)$, and mechanical ventilation/mortality $(p<0.0001)$ were lower in epoch 4 patients compared to epoch 1-3 patients (Supplemental Figures 2a, 2b, 2c, respectively). Rates of being discharged alive within 3, 5, and 7 days of admission were significantly higher in epoch 4 patients compared to epoch 1-3 patients (Table 3).

Relative Risks of In-Hospital Outcomes. In propensity score adjusted Cox regression models, the estimated in-hospital relative risks (RR: expressed as hazard ratios) of the composite outcome mechanical ventilation/mortality $(\mathrm{RR}=0.67,95 \% \mathrm{CI}: 0.48,0.93)$, use of mechanical ventilation $(\mathrm{RR}=0.64,95 \% \mathrm{CI}: 0.42,0.96)$, and mortality, $(\mathrm{RR}=0.81,95 \% \mathrm{CI}: 0.53,1.23)$ were lower in epoch 4 patients compared to epoch 1-3 patients (Table 4). In propensity adjusted logistic regression models, RRs (expressed as odds ratios) of being discharged alive within 3, 5, or 7 days of admission were higher in epoch 4 patients compared to epoch 1-3 patients, ranging from an estimated 1.6- to 1.7-fold higher odds of shorter length of stay in epoch 4 patients (Table 4).

In sensitivity analyses using 1:1 propensity matched group patients (epoch 4 vs. epochs 1-3), presenting patient characteristics were similar (see Supplemental Table S3), and Cox and logistic regression estimates favoring better in-hospital outcomes in epoch 4 patients were similar (see Supplementary Table S4). Outcome results using propensity inverse probability 
weighting Supplementary Table S4) were similar. A comparison of outcome results across all methods of analysis is depicted in Supplemental Figure 2, which shows similar results across all methods.

Relative Risks of In-Hospital Outcomes by Age. As seen in Table 5, the in-hospital outcome changes observed in epoch 4 versus epoch 1-3 patients varied by age. Specifically, in the age groups of less than 60 years of age or 60 to 74 years of age, the adjusted risk of inhospital mechanical ventilation/mortality was approximately $50 \%$ lower in epoch 4 patients compared to epoch 1-3 patients. In contrast, the adjusted risk of in-hospital mechanical ventilation/mortality among patients 75 years of age and older was similar between epoch 4 versus epoch 1-3 patients.

Among patients less than 60 years of age, the adjusted odds of having a hospital stay of $\leq 3$ days (discharged alive) were approximately 1.8 fold higher in epoch 4 patients, and were even larger for a hospital stay of $\leq 5$ days (about 2.1-fold higher) or $\leq 7$ days (about 2.6-fold higher). Patients age 60 to less than 75 years also tended to have a shorter length of stay in epoch 4, whereas there were no differences by epoch in lengh of for patients aged 75 and older.

\section{DISCUSSION}

Among COVID-19 patients hospitalized starting in March of 2020, our analyses show recent (epoch 4: June $19^{\text {th }}$ to August $31^{\text {st }}, 2020$ ) decreases in rates of mechanical ventilation, mortality, and hospital length of stay, compared with earlier time periods. These results were observed principally in hospitalized patients under the age of 75, and are consistent with some, ${ }^{1-}$ 3,39-42 but not all, ${ }^{4}$ recent non-peer-reviewed reports. The better hospital outcomes observed do 
medRxiv preprint doi: https://doi.org/10.1101/2020.09.29.20203802; this version posted September 29, 2020. The copyright holder for this

It is made available under a CC-BY-NC-ND 4.0 International license .

not appear to be attributable to differences in baseline characteristics of hospitalized COVID-19 patients, which were minimal and controlled for statistically with multiple analytic approaches.

In our large, representative health care system, we observed marked temporal changes in clinical management of patients, The most notable changes in clinical management of patients in the most recent interval was s higher use of dexamethasone (and glucocorticoids overall), higher use of anticoagulants, earlier initiation of dexamethasone, glucocorticoids as a class, and use of anticoagulants. The observed treatment strategy of earlier and significantly more frequent use of dexamethasone in patients in the UPMC system likely was triggered by the July 2020 release of the RECOVERY trial, ${ }^{9}$ which showed lower 28 -day mortality in patients who were receiving oxygen with or without invasive mechanical ventilation, and who received dexamethasone as compared to placebo. Our observed practice pattern of more frequent use of steroids is also consistent with a recently published (September 2,2020) meta-analysis of six trials involving random assignment of different steroids (dexamethasone, hydrocortisone, methylprednisolone) compared to placebo, and approximately $30 \%$ lower risk of 28-day mortality among patients treated with steroids..$^{25}$

Effect of Treatment Changes in Clinical Practice. An obvious question that arises from the present analysis is to what extent did the recent changes in clinical practice (e.g. greater use and earlier initiation of steroids and anticoagulants) lead to overall lower rates of mechanical ventilation and hospital mortality, as well shorter length of hospital stay? Unfortunately, this type of question is difficult to answer with an observational dataset. Specifically, in non-randomized settings, there is potential confounding by indication (indication bias) when comparing different treatment approaches. It is nearly impossible to determine whether a given treatment approach was initiated a priori, as opposed to preferentially in response to patient disease severity and/or 
hospital course, thereby rendering comparisons of such treated patients to those who did not receive the treatment as potentially biased. ${ }^{26,27}$ As recently articulated, we believe caution is wise and causality uncertain though possible with these observational data. ${ }^{28}$ Our data provide a rationale for potential conduct of new RCTs, particularly pragmatic and adaptive types ${ }^{29}$ of trials that can quickly study questions, such as the timing in which steroids and anticoagulants are administered among COVID-19 hospitalized patients.

Variation in Outcomes by Age. The present analysis indicated that the better in-hospital outcomes observed in recent hospitalized COVID-19 patients (epoch 4) were principally evident in patients under the age of 75, and largely not evident among those 75 years of age and older. Multiple potential explanations exist for these apparent differential results. First may be the clinical decision for potential use of mechanical ventilation. A report of 5,700 COVID-19 patients admitted to 12 hospitals in New York showed high rates of mortality for mechanically ventilated patients over the age of $65 .{ }^{30}$ These findings comport with indications that some physicians may be reluctant to initiate mechanical ventilation in elderly patients as compared to younger patients who typically present with fewer comorbidities, (e.g. $\left.{ }^{31}\right)$ potential medical ethics arguments made for rationing use of ventilators by age, ${ }^{32,33}$ and from the patient perspective, possibility that some elderly patients (coupled with family member input) may be particularly likely to expressly state orders against the use of mechanical ventilation. (e.g. ${ }^{34-36}$ ) These types of competing influences may blur assessment of the true clinical risk of mechanical ventilation in elderly COVID-19 hospitalized patients. With respect to less indication in our dataset of a mortality reduction in recently treated elderly COVID-19 patients, these findings may represent the greater challenge and complexity in treating elderly hospitalized COVID-19 patients who may be frail and have extensive comorbidities. This is consistent with reports of age being an 
medRxiv preprint doi: https://doi.org/10.1101/2020.09.29.20203802; this version posted September 29, 2020. The copyright holder for this

It is made available under a CC-BY-NC-ND 4.0 International license .

independent risk factor for COVID-19 mortality $^{37}$ as well as for higher levels of inflammatory dysfunction markers and weakened immune response ${ }^{38}$.

Strengths and Limitations. Strengths of this study include analysis of a large, heterogenous patient population (e.g. enhances generalizability), standardized collection of realworld data and algorithmic coding of variables harmonized in a clinical data warehouse collected for non-research purposes (e.g. reduces potential reporting and ascertainment bias), and access to a very large battery of sociodemographic, medical history, medication use, and clinical practice and outcome variables available for analysis. A limitation is that we extracted all variables from the EHR of a multisite health care system, making fidelity concerns persist. All current data are observational and cannot determine causality. We also did not collect data to inform changes in host biology or viral pathogenesis over time, and we did not attempt to assess other external factors, such as seasonal effects of temperature and humidity variation, and possible patientspecific directives against the use of mechanical ventilation. Lastly, the present analysis includes a small percentage of hospitalized patients $(<13 \%)$ enrolled in clinical trials, including potential randomization to either hydroxychloroquine, steroids, immunomodulators, convalescent plasma, or placebo. While a potential impact, we think that effect is modest if at all present.

Conclusions. Recently treated hospitalized COVID-19 patients in our large health care system have overall lower rates of mechanical ventilation/in-hospital mortality and shorter length of hospital stay compared to earlier intervals. The extent to which these improved patient outcomes are related to recent changing clinical practice (i.e. greater and earlier use of steroids and anticoagulants) is unknown but an opportunity for rigorous future controlled trials. 


\section{Figure Legends.}

\section{Figure 1.}

Histogram of the average number of COVID-19 tests reported in the UPMC system during the study period. The color coding depicts the time periods in which the 4 epochs were defined for comparative analyses.

\section{Figure 2.}

Stacked bar chart of timing of use and steroids and anticoagulants comparing recently treated epoch 4 patients to earlier patients treated in epochs 1-3. Light shading: drug initiated on same day as hospital admission; Medium shading: drug administered on the day after hospital admission; Dark shading: drug administered 2 or more days after hospital admission.

\section{Supplemental Figure 1.}

Bar chart of the average number of hospital admissions during the four different study-defined Epochs: Epoch 1: March 14-March 31, 2020; Epoch 2: April 1-May 15, 2020; Epoch 3: May 16June 28, 2020; Epoch 4: June 29-August 31, 2020.

\section{Supplemental Figure 2.}

Kaplan-Meier plots of survival free probabilities of in-hospital mechanical ventilation (2a), mortality (2b), and mechanical ventilation/mortality (2c) stratified by epoch 1-3 patients (blue line) versus epoch 4 patients (red line). 


\section{Supplemental Figure 3.}

Plot of relative risks (RR) of in-hospital outcomes comparing epoch 4 patients to epoch 1-3 patients. The filled symbols represent the RR estimate; the lower and upper end of the vertical lines represent the lower and upper limits of the $95 \%$ confidence interval. Symbol interpretation is as follows: rectangle (unadjusted estimate); diamond (propensity score adjustment as a continuous variable); triangle (propensity score with inverse probability weighting (IPW)); circle (1:1 matched propensity score). Composite: in-hospital mechanical ventilation/mortality, LOS3: length of stay $\leq 3$ days; LOS5: length of stay $\leq 5$ days; LOS7: length of stay $\leq 7$ days. 


\section{References}

1. Harris JE. COVID-19 case mortality rates continue to decline in Florida. MedRxiv: The Preprint Server for the Health Sciences; doi: https://doi.org/10.1101/2020.08.03.20167338. posted August 4, 2020.

2. $\quad$ Le Page M. Is coronavirus becoming less deadly? New Scientist; Volume 247, Issue 3291, 18 July 2020, Page 9. Accessed September 24, 2020 at: https://www.sciencedirect.com/science/article/pii/S0262407920312276

3. Oke J, Howdon D, Heneghan C. Declining COVID-19 case fatality rates across all ages: analysis of German data. Oxford University Centre for Evidence Based Medicine (CEBM); September 9, 2020. Accessed September 24, 2020 at: https://www.cebm.net/covid-19/declining-covid-19-case-fatality-rates-across-all-agesanalysis-of-german-data/

4. Rothman DL, Rothman JE, Bossard G. Is Covid-19 growing less lethal? The infection fatality rate says 'no' First Opinion; August 24, 2020. Accessed September 24, 2020 at: https://www.statnews.com/2020/08/24/infection-fatality-rate-shows-covid-19-isntgetting-less-deadly/

5. Centers for Disease Control. COVID-Net: A weekly summary of US COVID-19 hospitalization data. Accessed August 27, 2020 at: https://gis.cdc.gov/grasp/COVIDNet/COVID19_5.html

6. Dondorp AM, Hayat M, Aryal D, Beane A, Schultz MJ. Respiratory support in COVID19 patients, with a focus on resource-limited settings. American Journal of Tropical Medicine and Hygiene 2020;102(6):1191-1197. 
medRxiv preprint doi: https://doi.org/10.1101/2020.09.29.20203802; this version posted September 29, 2020. The copyright holder for this preprint (which was not certified by peer review) is the author/funder, who has granted medRxiv a license to display the preprint in perpetuity.

It is made available under a CC-BY-NC-ND 4.0 International license .

7. Tang N, Bai H, Chen X, Gong J, Li D, Sun Z. Anticoagulant treatment is associated with decreased mortality in severe coronavirus disease 2019 patients with coagulopathy. Journal of Thrombosis and Haemostasis 2020;18(5):1094-1099.

8. Trinh M, Chang DR, Govindarajulu US, Kane E, Fuster V, Kohli-Seth R, Ahmed S, Levin MA, Chen MD. Therapeutic anticoagulation is associated with decreased mortality in mechanically ventilated COVID-19 patients. MedRxiv: The Preprint Server for the Health Sciences; doi: https://doi.org/10.1101/2020.05.30.20117929

9. RECOVERY Collaborative Group, Horby P, Lim WS, et al. Dexamethasone in hospitalized Patients with Covid-19 - preliminary report [published online ahead of print, 2020 July 17]. New England Journal of Medicine. 2020;NEJM oa2021436. doi:10.1056/NEJMoa2021436.

10. Xiang Z, Liu J, Shi D, et al. Glucocorticoids improve severe or critical COVID-19 by activating ACE2 and reducing IL-6 levels. International Journal of Biological Sciences. 2020;16(13):2382-2391. Published 2020 Jun 27. doi:10.7150/ijbs.47652

11. Chatterjee K, Wu CP, Bhardwaj A, Siuba M. Steroids in COVID-19: An overview. Cleveland Clinic Journal of Medicine, published online ahead of print, Aug 20, 2020. 2020;10.3949/ccjm.87a.ccc059. doi:10.3949/ccjm.87a.ccc059

12. Fadel R, Morrison AR, Vahia A, et al. Early short course corticosteroids in hospitalized patients with COVID-19. Clinical Infectious Diseases. Published online ahead of print, May 19, 2020. ciaa601. doi:10.1093/cid/ciaa601.

13. Firouzabadi MD, Firouzabadi DF, Goudarzi S, Jahandideh H, Roomiani M. Has the chief complaint of patients with COVID-19 disease changed over time? [published online 
medRxiv preprint doi: https://doi.org/10.1101/2020.09.29.20203802; this version posted September 29, 2020. The copyright holder for this preprint (which was not certified by peer review) is the author/funder, who has granted medRxiv a license to display the preprint in perpetuity.

It is made available under a CC-BY-NC-ND 4.0 International license .

ahead of print, 2020 Jun 7]. Med Hypotheses. 2020;144:109974.

doi:10.1016/j.mehy.2020.109974

14. Ma Y, Zhao Y, Liu J, He X, Wang B, Shihua F, Yan J, Niu J, Luo B. Effects of temperature variation and humidity on the death of COVID-19 in Wuhan, China. Science of the Total Environment 724 (2020) 138226.

15. Scientific American July 16 ,2020. Second coronavirus strain may be more infectiousbut some scientists are skeptical. Accessed August 31, 2020 at:

https://www.scientificamerican.com/article/second-coronavirus-strain-may-be-moreinfectious-but-some-scientists-are-skeptical/

16. Korber B, Fischer WM, Gnanakaran S, et al. Tracking changes in SARS-CoV-2 spike: evidence that D614G increases infectivity of the COVID-19 virus. Cell 2020;182(4):812827.e19.

17. Centers for Disease Control and Prevention. Testing strategy for coronavirus (COVID19) in high-density critical infrastructure workplaces after a COVID-19 case is identified. Accessed August 31, 2020at: https://www.cdc.gov/coronavirus/2019ncov/community/worker-safety-support/hd-testing.html

18. Dora AV, Winnett A, Jatt LP, et al., Universal and serial laboratory testing for SARSCoV-2 at a long-term care skilled nursing facility for veterans - Los Angeles, California, 2020. The Morbidity and Mortality Weekly Report (MMWR) 2020; 69(21): 651-655.

19. Centers for Medicare \& Medicaid Services. Trump administration strengthens COVID-19 surveillance with new reporting and testing requirements for nursing homes, other providers. August 25, 2020. Accessed August 31, 2020 at: 
medRxiv preprint doi: https://doi.org/10.1101/2020.09.29.20203802; this version posted September 29, 2020. The copyright holder for this preprint (which was not certified by peer review) is the author/funder, who has granted medRxiv a license to display the preprint in perpetuity.

It is made available under a CC-BY-NC-ND 4.0 International license .

https://www.cms.gov/newsroom/press-releases/trump-administration-strengthens-covid-

$\underline{19-s u r v e i l l a n c e-n e w-r e p o r t i n g-a n d-t e s t i n g-r e q u i r e m e n t s ~}$

20. Forbes Magazine. July brings major changes for coronavirus testing and tracing of college athletes. July 2, 2020. Accessed August 31, 2020 at:

https://www.forbes.com/sites/karenweaver/2020/07/02/july-brings-major-changes-forcoronavirus-testing-and-tracing-of-college-athletes/\#3696f86b3da7

21. University of Pittsburgh Medical Center (UPMC). (2020). "Why UPMC?". Retrieved July 13, 2020, from www.upmc.com/about/why-upmc

22. Rosenbaum PR, Rubin DB. The central role of the propensity score in observational studies for causal effects. Biometrika 1983; 70: 41-55.

23. Austin PC. An introduction to propensity score methods for reducing the effects of confounding in observational studies. Multivariate Behavioral Research 2011; 46(3): $399-424$.

24. Benchimol EI, Smeeth L, Guttmann A, et al. The REporting of studies Conducted using Observational Routinely-collected health Data (RECORD) statement. PLoS Medicine 2015; 12(10):e1001885. Published 2015 Oct 6. doi:10.1371/journal.pmed.1001885

25. WHO Rapid Evidence Appraisal for COVID-19 Therapies (REACT)Working Group. Association between administration of systemic corticosteroids and mortality among critically ill patients with COVID-19. A meta-analysis. JAMA.

doi:10.1001/jama.2020.17023. Published online September 2, 2020.

26. Walker AM. Confounding by indication. Epidemiology 1996; 7: 335-336.

27. Joseph KS, Mehrabadi A, Lisonkova S. Confounding by indication and related concepts. Current Epidemiology Reports 2014; 1: 1-8. 
medRxiv preprint doi: https://doi.org/10.1101/2020.09.29.20203802; this version posted September 29, 2020. The copyright holder for this preprint (which was not certified by peer review) is the author/funder, who has granted medRxiv a license to display the preprint in perpetuity.

It is made available under a CC-BY-NC-ND 4.0 International license .

28. Califf RM. Weighing the benefits and risks of proliferating observational treatment assessments. Observational cacophony, randomized harmony. JAMA 2020; 324(7): 625626.

29. Angus DC. Optimizing the trade-off between learning and doing in a pandemic. JAMA. 2020;323(19):1895-1896. Doi:10.1001/jama.2020.4984

30. Richardson S, Hirsch JS, Narasimhan M, et al. Presenting characteristics, comorbidities, and outcomes among 5700 patients hospitalized with COVID-19 in the New York City area [published online ahead of print, 2020 Apr 22] [published correction appears in doi: 10.1001/jama.2020.7681]. JAMA. 2020;323(20):2052-2059. doi:10.1001/jama.2020.6775

31. Lieberman D, Nachshon L, Miloslavsky O, et al. Elderly patients undergoing mechanical ventilation in and out of intensive care units: a comparative, prospective study of 579 ventilations. Critical Care 2010;14(2): R48.

32. Miller FG. Why I support age-related rationing of ventilators for COVID-19 patients. Published in: Covid-19, Hastings Bioethics Forum, Health and Health Care, April 9, 2020; Accessed September 16: https://www.thehastingscenter.org/why-i-support-agerelated-rationing-of-ventilators-for-covid-19-patients/

33. LA Times, March 26, 2020. Who lives and who dies? With ventilators limited amid coronavirus, doctors might face hard choices. Accessed September 4, 2020 at: https://www.latimes.com/science/story/2020-03-26/coronavirus-ventilator-shortagechoice-health-care-doctors

34. Fried TR, Bradley EH, Towle VR, Allore H. Understanding the treatment preferences of seriously ill patients. New England Journal of Medicine 2002; 346(14):1061-1066. 
medRxiv preprint doi: https://doi.org/10.1101/2020.09.29.20203802; this version posted September 29, 2020. The copyright holder for this preprint (which was not certified by peer review) is the author/funder, who has granted medRxiv a license to display the preprint in perpetuity.

It is made available under a CC-BY-NC-ND 4.0 International license .

35. White DB, Lo B. A Framework for rationing ventilators and critical care beds during the COVID-19 pandemic. JAMA. 2020;323(18):1773-1774. doi:10.1001/jama.2020.5046

36. Modern Healthcare. May 12, 2020. 'No intubation': seniors fearful of COVID-19 are changing their living wills; Accessed September 4, 2020 at:

https://www.modernhealthcare.com/safety-quality/no-intubation-seniors-fearful-covid19-are-changing-their-living-wills

37. Williamson, E.J., Walker, A.J., Bhaskaran, K. et al. Factors associated with COVID-19related death using Open SAFELY. Nature 584, 430-436 (2020). https://doi.org/10.1038/s41586-020-2521-4

38. Mueller AL, McNamara MS, Sinclair DA. Why does COVID-19 disproportionately affect older people? Aging (Albany NY). 2020;12(10):9959-9981.

doi:10.18632/aging.103344

39. The Atlantic July 9, 2020. COVID-19 cases are rising, so why are deaths flatlining? Accessed September 3, 2020 at: https://www.theatlantic.com/ideas/archive/2020/07/whycovid-death-rate-down/613945/

40. Healthline. COVID-19 mortality is going down in ICUs - what this means for the pandemic. July 17, 2020, Accessed September 13, 2020 at:

https://www.healthline.com/health-news/covid-19-mortality-is-going-down-in-icus-what$\underline{\text { this-means-for-the-pandemic }}$

41. LA Times, August 9, 2020. As COVID-19 cases surge, patients are dying at a lower rate. Here's why. Accessed September 3, 2020 at: https://www.latimes.com/california/story/2020-08-09/covid-19-coronavirus-survival-rate$\underline{\text { improves }}$ 
medRxiv preprint doi: https://doi.org/10.1101/2020.09.29.20203802; this version posted September 29, 2020. The copyright holder for this preprint (which was not certified by peer review) is the author/funder, who has granted medRxiv a license to display the preprint in perpetuity.

It is made available under a CC-BY-NC-ND 4.0 International license .

42. Bodkin H. Covid death rates dropped as doctors rejected ventilators. The Telegraph, September 3, 2020. Accessed on September 8, 2020 at:

https://www.telegraph.co.uk/news/2020/09/03/covid-death-rates-dropped-doctorsrejected-ventilators/ 
Table 1. Comparison of Hospitalized COVID Patient Characteristics at Admission by Epoch

\begin{tabular}{|c|c|c|c|c|c|}
\hline Characteristic & $\begin{array}{c}\text { Epoch 1 } \\
\text { (March 14 - } \\
\text { March 31) } \\
(\mathrm{N}=72) \\
\end{array}$ & $\begin{array}{c}\text { Epoch 2 } \\
\text { (April 1- } \\
\text { May 15) } \\
(\mathrm{N}=\mathbf{2 0 3}) \\
\end{array}$ & $\begin{array}{l}\text { Epoch 3 } \\
\text { (May 16- } \\
\text { June 28) } \\
(\mathrm{N}=166) \\
\end{array}$ & $\begin{array}{c}\text { Epoch 4 } \\
\text { (June 29 } \\
\text { - August 31) } \\
(\mathbf{N}=635) \\
\end{array}$ & $\begin{array}{c}p \text { - } \\
\text { value }\end{array}$ \\
\hline Age, mean, SD & $63.5,17.4$ & $65.0,18.4$ & $63.0,20.6$ & $65.2,19.8$ & 0.5640 \\
\hline Female gender, $\%$ & 43.1 & 51.2 & 52.4 & 49.6 & 0.5864 \\
\hline Body mass index, mean, SD & $32.2,7.1$ & $34.2,9.9$ & $32.4,8.1$ & $32.0,8.3$ & 0.3501 \\
\hline \multicolumn{6}{|l|}{ Race, $\%$} \\
\hline White & 81.7 & 61.2 & 67.9 & 65.4 & 0.1066 \\
\hline Black & 16.9 & 34.8 & 28.5 & 30.6 & \\
\hline Other Race & 1.4 & 4.0 & 3.6 & 4.0 & \\
\hline UPMC Health Plan, \% & 40.3 & 25.6 & 33.7 & 40.5 & 0.0010 \\
\hline History of hypertension, $\%$ & 55.6 & 62.5 & 53.4 & 62.3 & 0.3226 \\
\hline History of hyperlipidemia, \% & 50.0 & 51.9 & 49.5 & 54.5 & 0.7703 \\
\hline History of diabetes, $\%$ & 22.2 & 38.5 & 29.1 & 38.4 & 0.0485 \\
\hline History of atrial fibrillation, $\%$ & 13.0 & 14.4 & 12.6 & 13.0 & 0.9809 \\
\hline History of congestive heart failure, $\%$ & 13.0 & 17.3 & 16.5 & 14.5 & 0.8293 \\
\hline History of major bleed, \% & 24.1 & 23.1 & 26.2 & 22.7 & 0.9024 \\
\hline \multicolumn{6}{|l|}{ History of cancer, $\%$} \\
\hline History of chronic kidney disease, $\%$ & 9.3 & 24.0 & 18.4 & 17.1 & 0.1292 \\
\hline History of chronic obstructive pulmonary disease, $\%$ & 18.5 & 26.9 & 10.7 & 25.1 & 0.0094 \\
\hline History of obstructive sleep apnea, \% & 24.1 & 24.0 & 20.4 & 22.7 & 0.9236 \\
\hline \multicolumn{6}{|l|}{ Most recent lab values, mean, SD } \\
\hline Systolic blood pressure (mmHg) & 125,14 & 128,20 & 127,18 & $131,17.8$ & 0.0997 \\
\hline Diastolic blood pressure (mmHg) & 74,13 & 75,12 & 73,12 & 76,12 & 0.2208 \\
\hline Total cholesterol (mg/dL) & 163,45 & 161,41 & 165,51 & 159,46 & 0.8658 \\
\hline Aspartate aminotransferase (AST)* & 35,36 & 46,51 & 43,45 & 40,52 & 0.1473 \\
\hline
\end{tabular}


Creatinine*

Ejection fraction

Hemoglobin

Lymphocytes

Neutrophils

Platelets*

Partial thromboplastin time (PTT)

Charlson Comorbidity Index score, mean, SD

Selected medications, $\%$

Angiotensin-converting enzyme (ACE) Inhibitor

Angiotensin II receptor blocker (ARB)

Calcium channel blocker

Beta Blocker

Aspirin

Antiplatelet

Statin

Warfarin

Anti-depressant

$\begin{array}{ccccc}1.2,1.0 & 1.5,1.8 & 1.4,1.1 & 1.4,1.2 & 0.0747 \\ 53,13 & 52,13 & 57,10 & 53,10 & 0.1954 \\ 13.0,1.8 & 12.6,2.2 & 12.0,2.6 & 12.7,2.0 & 0.0039 \\ 15.8,11.8 & 17.8,11.2 & 19.4,10.6 & 18.6,10.7 & 0.1720 \\ 75,13 & 73,13 & 69,12 & 71,13 & 0.0340 \\ 197,73 & 221,108 & 212,94 & 211,91 & 0.3048 \\ 41.5,22.7 & 32.8,4.1 & 41.7,22.6 & 38.3,9.0 & 0.2620 \\ 1.3,1.6 & 2.0,2.1 & 1.6,1.8 & 1.8,1.9 & 0.0802\end{array}$

$\begin{array}{ccccc}16.7 & 25.0 & 20.4 & 22.3 & 0.6557 \\ 16.7 & 12.5 & 8.7 & 14.7 & 0.3860 \\ 24.1 & 28.8 & 27.2 & 25.1 & 0.8527 \\ 29.6 & 44.2 & 42.7 & 38.6 & 0.2889 \\ 46.3 & 42.3 & 39.8 & 42.9 & 0.8852 \\ 33.3 & 31.7 & 32.0 & 32.5 & 0.9971 \\ 50.0 & 48.1 & 51.5 & 51.4 & 0.9391 \\ 7.4 & 7.7 & 6.8 & 4.7 & 0.5699 \\ 29.6 & 42.3 & 45.6 & 35.3 & 0.1012\end{array}$

*Due to high skew, comparisons by epoch were made by non-parametric Kruskal Wallis tests. PCP: primary care physician 
Table 2. Practice Patterns of Use of Drugs by Epoch*

\begin{tabular}{|c|c|c|c|c|c|}
\hline Characteristic & $\begin{array}{c}\text { March 14- } \\
\text { March 31 } \\
(\mathrm{N}=72)\end{array}$ & $\begin{array}{c}\text { April 1 - } \\
\text { May } 15 \\
(\mathrm{~N}=203)\end{array}$ & $\begin{array}{c}\text { May } 16- \\
\text { June } 28 \\
(\mathrm{~N}=166)\end{array}$ & $\begin{array}{c}\text { June 29- } \\
\text { August } 31 \\
(\mathrm{~N}=635)\end{array}$ & p-value \\
\hline Use of remdesivir, $\%$ & 0.0 & 3.9 & 31.3 & 17.8 & $<.0001$ \\
\hline Use of dexamethasone, $\%$ & 5.6 & 5.4 & 14.5 & 55.6 & $<.0001$ \\
\hline Use of hydrocortisone, \% & 2.8 & 11.3 & 6.6 & 3.3 & $<.0001$ \\
\hline Use of prednisone, $\%$ & 8.3 & 6.4 & 7.2 & 6.8 & 0.9499 \\
\hline Use of methylprednisolone, $\%$ & 8.3 & 10.3 & 9.6 & 9.0 & 0.931 \\
\hline Any steroid used, \% & 20.8 & 25.6 & 31.3 & 62.2 & $<.0001$ \\
\hline Use of heparin, \% & 68.1 & 73.4 & 71.1 & 79.2 & 0.0285 \\
\hline Use of anticoagulation, $\%$ & 73.6 & 83.3 & 75.3 & 86.5 & 0.0007 \\
\hline Days from admission to remdesivir, mean, SD &., & $4.8,2.9$ & $2.2,3.8$ & $1.7,2.4$ & 0.3734 \\
\hline Days from admission to dexamethasone, mean, SD & $3.8,6.2$ & $7.0,8.0$ & $4.6,7.6$ & $1.5,3.1$ & 0.0135 \\
\hline Days from admission to hydrocortisone, mean, SD & $14.5,10.6$ & $5.7,6.7$ & $1.6,1.4$ & $7.5,7.8$ & 0.6182 \\
\hline Days from admission to prednisone, mean, SD & $14.2,21.8$ & $2.9,4.6$ & $3.8,3.3$ & $4.3,7.1$ & 0.4186 \\
\hline Days from admission to methylprednisolone, $\mathrm{mn}, \mathrm{SD}$ & $8.5,18.4$ & $5.9,7.4$ & $3.3,4.8$ & $4.4,8.9$ & 0.1329 \\
\hline Days from admission to steroid use, mean, SD & $5.0,7.9$ & $4.3,6.5$ & $2.6,3.8$ & $1.3,2.9$ & $<.0001$ \\
\hline Days from admission to heparin, mean, SD & $1.8,3.0$ & $1.5,5.7$ & $1.2,2.4$ & $1.0,3.2$ & 0.0003 \\
\hline Days from admission to anticoagulation, mean, SD & $1.6,2.9$ & $1.0,1.3$ & $1.2,2.3$ & $0.8,1.6$ & 0.0005 \\
\hline
\end{tabular}

*For all days from admission variables, comparisons by epoch were made by non-parametric Wilcoxon continuity-corrected 2-sample tests comparing epochs 1-3 to epoch 4. 
Table 3. Practice Patterns of Use of Oxygen Support and Hospital Outcomes by COVID Epoch*

\begin{tabular}{|c|c|c|c|c|c|}
\hline Characteristic & $\begin{array}{c}\text { March 14- } \\
\text { March } 31 \\
(\mathrm{~N}=72) \\
\end{array}$ & $\begin{array}{l}\text { April 1- } \\
\text { May } 15 \\
(\mathrm{~N}=203)\end{array}$ & $\begin{array}{c}\text { May } 16- \\
\text { June } 28 \\
(\mathrm{~N}=166)\end{array}$ & $\begin{array}{c}\text { June } 29- \\
\text { August } 31 \\
(\mathrm{~N}=635)\end{array}$ & p-value \\
\hline Use of oxygen, $\%$ & 65.3 & 72.9 & 59.0 & 60.2 & 0.0075 \\
\hline Use of high flow nasal cannula, $\%$ & 0.0 & 0.0 & 0.0 & 0.2 & 0.8743 \\
\hline Use of BIPAP and CPAP, \% & 5.6 & 16.3 & 15.7 & 16.1 & 0.1266 \\
\hline Use of ventilation, $\%$ & 20.8 & 22.2 & 16.9 & 11.7 & 0.0011 \\
\hline No use of oxygen & 34.7 & 26.6 & 40.4 & 38.7 & \\
\hline Use of oxygen therapy & 43.1 & 43.3 & 33.7 & 39.7 & \\
\hline Use of both BIPAP and CPAP & 1.4 & 7.9 & 9.0 & 9.9 & \\
\hline Use of mechanical ventilation* & 20.8 & 22.2 & 16.9 & 11.7 & \\
\hline Use of drug aerosol therapy, $\%$ & 19.4 & 16.3 & 16.9 & 20.2 & 0.5633 \\
\hline Use of general respiratory care treatments, $\%$ & 11.1 & 14.8 & 9.0 & 13.9 & 0.3233 \\
\hline Days admission to both BIPAP and CPAP, mean, SD & $31.3,48.1$ & $2.0,3.7$ & $4.3,5.3$ & $4.2,6.7$ & 0.2305 \\
\hline Days admission to ventilation, mean, SD & $2.1,2.5$ & $1.9,2.2$ & $2.3,3.4$ & $3.6,4.5$ & 0.0242 \\
\hline Days admission to drug aerosol therapy, mean, SD & $5.6,7.3$ & $7.5,8.8$ & $9.2,10.4$ & $4.0,5.8$ & 0.0039 \\
\hline Days admission to general resp care tx, mean, SD & $6.5,7.2$ & $9.3,15.2$ & $12.4,13.4$ & $5.9,7.2$ & 0.2816 \\
\hline In-hospital mortality, \%** & 19.4 & 23.6 & 14.5 & 10.2 & $<.0001$ \\
\hline In-hospital ventilation/mortality, $\% * *$ & 30.6 & 35.0 & 23.5 & 17.3 & $<.0001$ \\
\hline LOS $<=3$ days (discharged alive), $\%$ & 26.4 & 21.7 & 23.8 & 31.3 & 0.0373 \\
\hline LOS $<=5$ days (discharged alive), $\%$ & 41.7 & 32.5 & 37.2 & 47.1 & 0.002 \\
\hline LOS $<=7$ days (discharged alive), $\%$ & 45.8 & 41.4 & 49.4 & 60.6 & $<.0001$ \\
\hline
\end{tabular}

*For all days from admission variables, comparisons by epoch were made by non-parametric Wilcoxon continuity-corrected 2-sample tests comparing epochs 1-3 to epoch 4. **Some patients in epoch 4 (June 29-August 31) have yet to be discharged, hence, crude outcomes rates should be cautiously interpreted. BIPAP: Bilevel Positive Airway Pressure. CPAP: Continuous positive airway pressure. LOS: length of stay. 
Table 4. Relative Risks* of In-Hospital Outcomes Comparing Epoch 4 (Recent) to Epoch 1/2/3 (Earlier) Treated COVID-19 Patients

\begin{tabular}{lcccc}
\hline & \multicolumn{2}{c}{ Unadjusted } & \multicolumn{2}{c}{ Adjusted } \\
\cline { 2 - 5 } & $\begin{array}{c}\text { Patients with } \\
\text { All Patients } \\
\text { (N=1,076) }\end{array}$ & $\begin{array}{c}\text { Covariate Data } \\
(\mathbf{N = 6 8 3 )}\end{array}$ & $\begin{array}{c}\text { Propensity Score } \\
\text { Adjustment } \\
\text { Outcome }\end{array}$ & $\mathbf{R = 6 8 3 )}$ \\
\hline In-hospital ventilation/mortality & 0.56 & 0.66 & 0.67 & $0.48,0.93$ \\
In-hospital ventilation & 0.57 & 0.66 & 0.62 & $0.41,0.94$ \\
In-hospital mortality & 0.69 & 0.80 & 0.82 & 0.54 .1 .25 \\
LOS $\leq 3$ days (alive)** & 1.50 & 1.65 & 1.60 & $1.10,2.32$ \\
LOS $\leq 5$ days (alive)** & 1.60 & 1.62 & 1.59 & $1.13,2.23$ \\
LOS $\leq 7$ days (alive)** & 1.87 & 1.80 & 1.72 & $1.23,2.41$ \\
\hline
\end{tabular}

*For in-hospital ventilation and mortality, relative risk (RR) estimates are presented as hazard ratios. For length of stay (LOS), RR estimates are presented as odds ratios. **For length of stay, sample sizes ranged from 977 to 986 for the all patients in undajusted analyses, and from 618 to 626 for the adjusted analysis among patients with covariate data. The adjusted estimates are based on use of the propensity score as a continuous variable. 
medRxiv preprint doi: https://doi.org/10.1101/2020.09.29.20203802; this version posted September 29, 2020. The copyright holder for this preprint (which was not certified by peer review) is the author/funder, who has granted medRxiv a license to display the preprint in perpetuity.

It is made available under a CC-BY-NC-ND 4.0 International license .

Table 5. Relative Risks* of In-Hopsital Outcomes Comparing Epoch 4 (Current) to Epoch 1/2/3 (Earlier) COVID-19 Patients by Age Groups

\begin{tabular}{|c|c|c|c|c|}
\hline \multirow[t]{2}{*}{ Outcome / Age Group } & \multirow[t]{2}{*}{$\mathbf{N}$} & \multirow[t]{2}{*}{$\begin{array}{c}\# \\
\text { Events }\end{array}$} & \multicolumn{2}{|c|}{$\begin{array}{c}\text { Propensity Score } \\
\text { Adjustment }\end{array}$} \\
\hline & & & $\mathbf{R R}$ & $95 \% \mathrm{CI}$ \\
\hline \multicolumn{5}{|l|}{ Mechanical ventilation/mortality } \\
\hline Less than 60 years of age & 233 & 30 & 0.45 & $0.22,0.95$ \\
\hline 60 to less than 75 years of age & 207 & 54 & 0.52 & $0.29,1.93$ \\
\hline 75 years of age and older & 243 & 71 & 0.99 & $0.58,1.66$ \\
\hline \multicolumn{5}{|l|}{ Mechanical ventilation } \\
\hline Less than 60 years of age & 233 & 28 & 0.44 & $0.21,0.95$ \\
\hline 60 to less than 75 years of age & 207 & 40 & 0.55 & $0.28,1.07$ \\
\hline 75 years of age and older & 243 & 34 & 1.14 & 0.51 .2 .55 \\
\hline \multicolumn{5}{|l|}{ In-hospital mortality } \\
\hline Less than 60 years of age & 233 & 9 & 0.59 & $0.14,2.41$ \\
\hline 60 to less than 75 years of age & 207 & 32 & 0.47 & $0.21,1.05$ \\
\hline 75 years of age and older & 243 & 58 & 0.91 & $0.52,1.62$ \\
\hline \multicolumn{5}{|l|}{ LOS $\leq 3$ days (alive) } \\
\hline Less than 60 years of age & 217 & 104 & 1.81 & $1.04,3.15$ \\
\hline 60 to less than 75 years of age & 188 & 43 & 1.80 & $0.85,3.83$ \\
\hline 75 years of age and older & 221 & 43 & 1.23 & $0.56,2.67$ \\
\hline \multicolumn{5}{|l|}{ LOS $\leq 5$ days (alive) } \\
\hline Less than 60 years of age & 215 & 137 & 2.14 & $1.20,3.79$ \\
\hline 60 to less than 75 years of age & 188 & 67 & 1.23 & $0.64,2.35$ \\
\hline 75 years of age and older & 220 & 80 & 1.45 & $0.77,2.73$ \\
\hline \multicolumn{5}{|l|}{ LOS $\leq 7$ days (alive) } \\
\hline Less than 60 years of age & 214 & 154 & 2.63 & $1.42,4.88$ \\
\hline 60 to less than 75 years of age & 186 & 94 & 1.90 & $1.01,3.55$ \\
\hline 75 years of age and older & 218 & 95 & 1.23 & $0.67,2.26$ \\
\hline
\end{tabular}

*For in-hospital ventilation and mortality, relative risk (RR) estimates are presented as hazard ratios. For length of stay (LOS), RR estimates are presented as odds ratios. The adjusted estimates are based on use of the propensity score as a continuous variable. 
medRxiv preprint doi: https://doi.org/10.1101/2020.09.29.20203802; this version posted September 29, 2020. The copyright holder for this preprint (which was not certified by peer review) is the author/funder, who has granted medRxiv a license to display the preprint in perpetuity.

It is made available under a CC-BY-NC-ND 4.0 International license .

\section{Count of Tests by Period}

Average \# of Tests per Day: 349

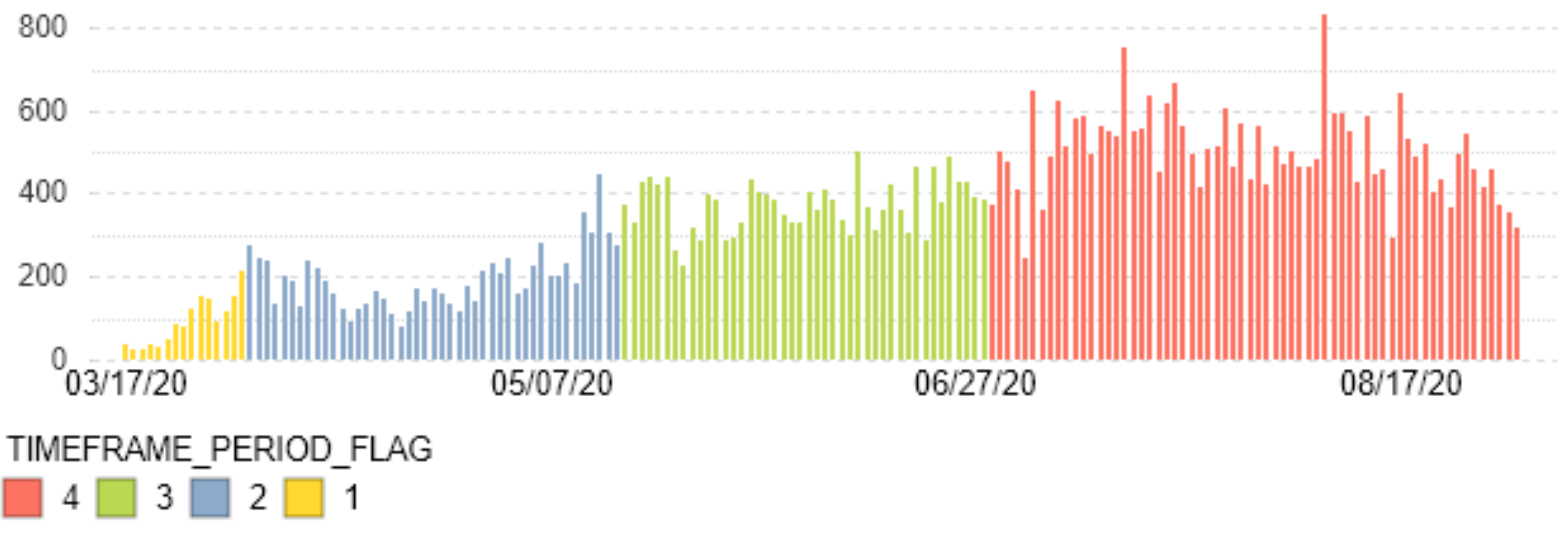

\section{Figure 1}




\section{Timing of Start of Steroid Use}

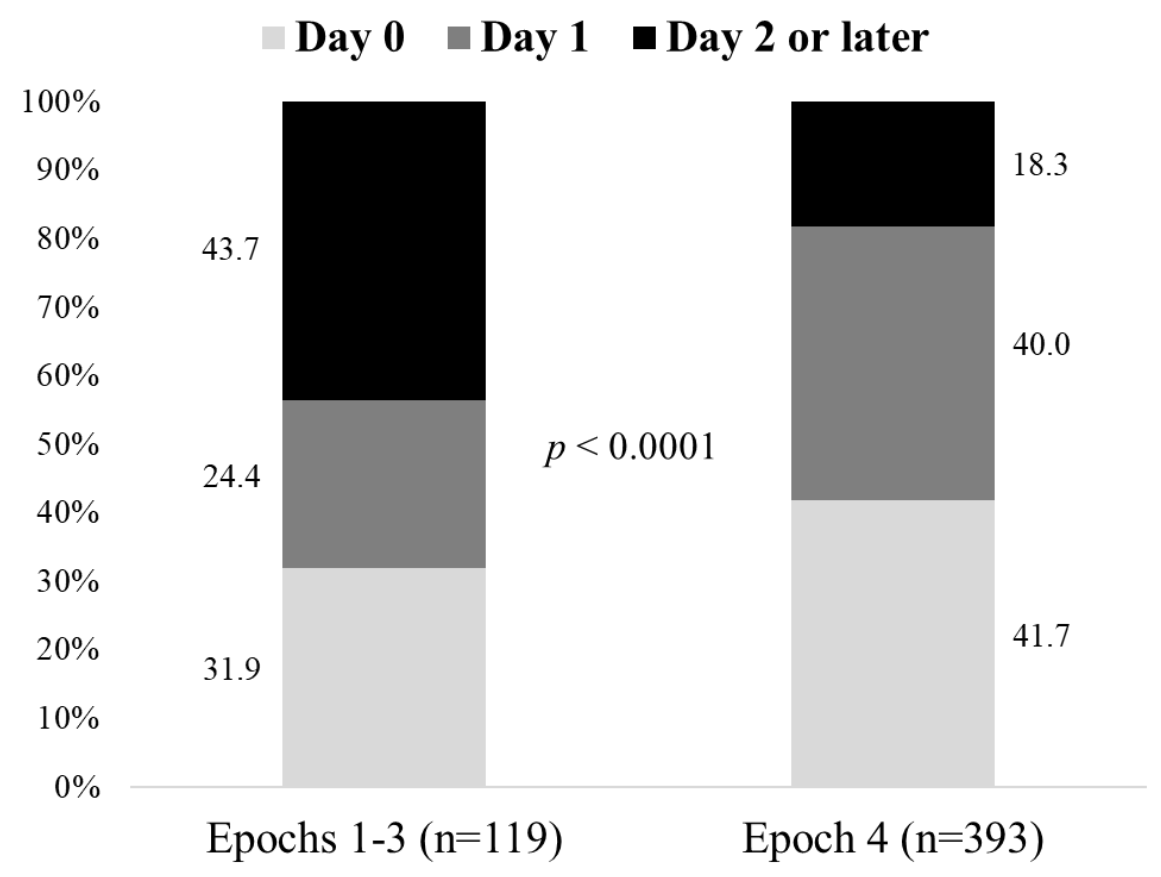

Figure 2
Timing of Start of Anticoagulation Use

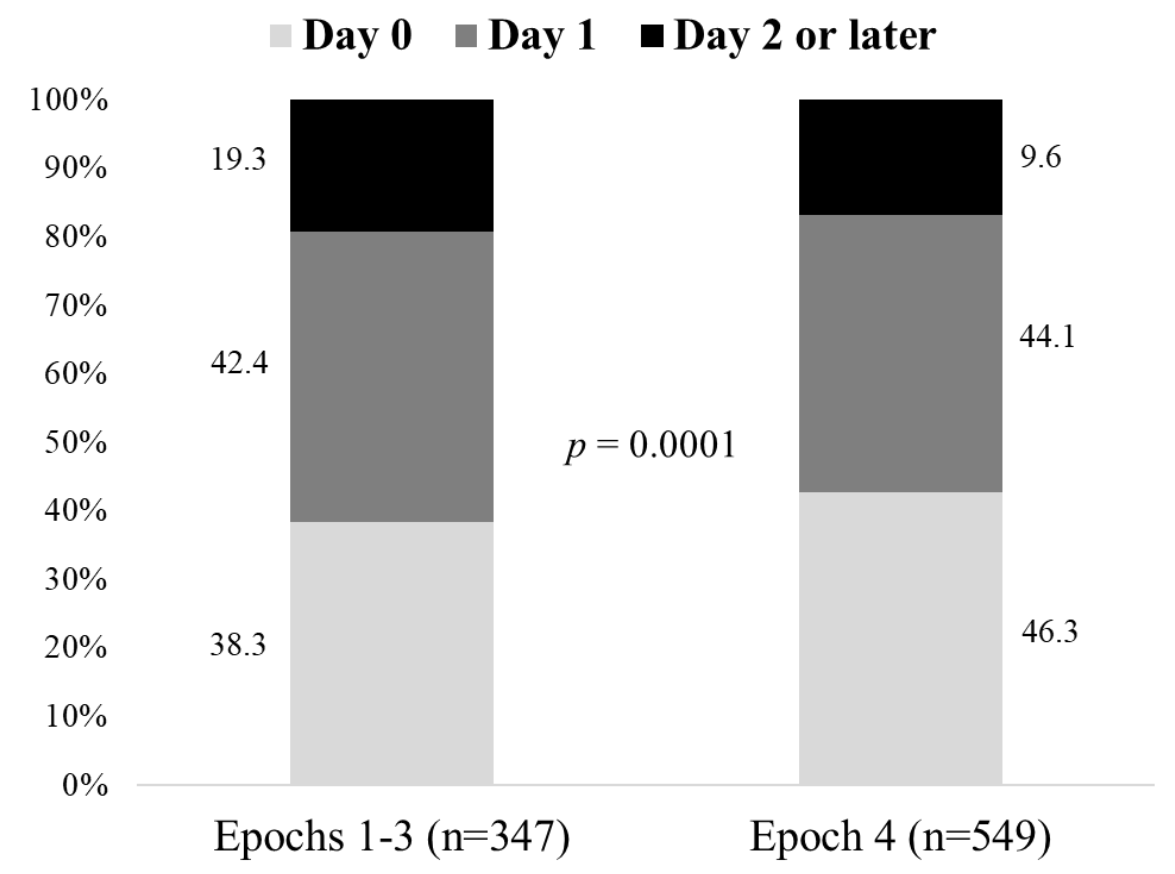

